\title{
The Affecting Factors of Implementation of Expanding Maternal and Neonatal Survival Program in Determining Midwifery in Kebumen, Indonesia
}

\author{
Wulan Rahmadhani ${ }^{1}$ \\ \{wulan@stikesmuhgombong.ac.id ${ }^{1}$ \} \\ Department of Midwifery, Sekolah Tinggi Ilmu Kesehatan Muhammadiyah Gombong, Indonesia ${ }^{1}$
}

\begin{abstract}
Maternal mortality rate has notably decreased after the implementation of the Expanding Maternal and Neonatal Survival (EMAS) program that manages to increase the effectiveness and accountability of midwives' performance. The study aims to investigate factors affecting the implementation of the Expanding Maternal and Neonatal Survival (EMAS) program in midwives' performance. This study applied a cross-sectional design. It involved 822 midwives. The data were collected from demographic information about midwives' performance. Then, the obtained data were analyzed using bivariate analysis techniques to show the relationship between the dependent and independent variables. It used a non-parametric test of two independent samples with Chi-Square with a significance limit or p-values of $<0.05$ and Confidence Interval (CI) of $95 \%$. There was a relationship between training, supervision, motivation, and midwives' performance. The study revealed the detail values for training (p-value: 0.047, OR: 4.48, 95\% CI: 1.016-19.723), supervision (p-value: $<0.001$, OR values: $6.83,95 \%$ CI: $2.625-17.747$ ), and motivation (pvalue: 0.002 , OR: 4.08 , and 95\% CI: 1.709-9.756). Midwives' performance becomes an issue in the implementation of EMAS program. Midwives have to improve their attitudes and motivation in working for the implementation of this program
\end{abstract}

Keywords: Midwifery, Expanding Maternal and Neonatal Survival program, Performance

\section{Introduction}

In 2017, approximately 810 women died from preventable causes related to pregnancy and childbirth [1]. At the same time, between 2000 and 2017, Southern Asia achieved the highest overall reduction in the maternal mortality rate of $60 \%$ (from 384 to 157). Additionally, four other sub-regions roughly halved their maternal mortality rate during this period, namely, Central Asia, Eastern Asia, Europe, and Northern Africa. Overall, the maternal mortality rate in less-developed countries declined by lower than $50 \%$ [1].

In Indonesia, the success of maternal health efforts can be seen from the indicators of maternal mortality [2]. The indicator of maternal mortality is the number of maternal deaths during pregnancy, childbirth, and post-partum period caused by pregnancy, childbirth, and postpartum period or its management except for other causes such as accidents or falls in every 100.000 live births [3]. Indeed, those indicators are not only used to assess maternal health programs, but also to assess the level of public health due to its sensitivity to improve health services, both in terms of accessibility and quality [2]. In general, there has been a decline in the maternal mortality rate in Indonesia from 390 cases in 1991 to 305 cases in 2015 [4]. 
In 2012, the Ministry of Health of the Republic of Indonesia launched a program called Expanding Maternal and Neonatal Survival (EMAS) to accelerate the reduction in maternal and neonatal mortality rate. This program aims to improve the quality of obstetric emergencies and newborn services as well as to strengthen an efficient and effective referral system between midwives, primary health care, and hospitals [4]. Efforts to accelerate the reduction in maternal mortality can be carried out by ensuring that every mother can access quality maternal health services, such as antenatal care, birth delivery assisted by trained midwives in health care facilities, postpartum care for mother and baby, special care and referral if any complications, ease of maternity leave, and family planning services [5]. The following section presents maternal health efforts consisting of maternal health services, Tetanus Toxoid immunization services for women of reproductive age and pregnant women, childbirth service, postpartum services, and the implementation of Kelas Ibu Hamil (pregnancy class) and childbirth planning programs by village midwives to prevent complications, and contraceptive services [6].

Health service performance is an important factor in efforts to improve the quality of public health [7]. The low performance of health services can be seen from the antenatal services performed by village midwives based on the indicator of the proportion of childbirth assistance. The presence of midwives in the villages is expected to overcome geographical disparities, while midwife contact with the community is expected to reduce health information gaps [8]. Placement of midwives in villages and the level of utilization of midwifery services are influenced by the age and ability of the midwives. They become determinant factors for the community's acceptance [6].

First Visit (K1) is the patient's first visit to the health care worker/facility, while Fourth Visit (K4) is the patient's fourth visit to the health care worker/facility [9]. K1 coverage is the number of pregnant women who have accessed antenatal care for the first time compared to the target number of pregnant women in a working area during a year [10]. On the other hand, K4 coverage is the number of pregnant women who have accessed standard antenatal care at least four times based on the recommended schedule in each trimester compared to the target number of pregnant women in a working area in a year [9]. The indicator shows access to health services for pregnant women and their compliance in accessing antenatal services. During 2006-2017, the K4 coverage tended to increase even though 11 provinces have not reached the target [11].

The challenges on the implementation of health services for pregnant women are not only access but also the quality of services [12]. Indeed, the quality of services has to be improved, including the provision of all health services components for pregnant women during the antenatal visit [13]. In terms of availability of health facilities, up to December 2017, Kebumen District has 544 village midwives, and 5 of them working in remote areas [14]. Ideally, the village midwives have to be supported by good accessibility, particularly related to geographical aspects and better transportation infrastructure [9].

Based on the data of the Ministry of Health of the Republic of Indonesia, $83.67 \%$ of pregnant women whose childbirth was assisted by midwives including village midwives in the health care facilities [15]. Analysis of maternal mortality rate proved that the maternal mortality rate is closely related to the presence of the midwives and available facilities [15]. Childbirth assisted by a midwife showed a significant contribution to the reduction of maternal death risk. Besides, if the childbirth is performed in a health facility, it can reduce the maternal death risk too. Therefore, this study aims to investigate factors affecting the implementation of the Expanding Maternal and Neonatal Survival (EMAS) program and midwives' performance. 


\section{Method}

This cross-sectional study collected data by distributing a questionnaire via the internet. The data collection was started on May 7, 2019, and completed on November 28, 2019. The researcher shared the questionnaire link from Questback.com on Facebook pages. It was conducted in Kebumen District, Central Java Province. This district covers 26 sub-districts and 449 villages with a total of 1420 midwives. It involved 822 samples selected using purposive sampling techniques. The inclusion criteria were village midwives working for $\geq 1$ year with good reading and writing skills and willing to participate in the study. In the last section of the questionnaire, the respondents were required to respond to questions regarding the appropriateness of midwife performance, age, tenure, education, training, rewards, supervision, facilities, leadership, attitude, and motivation. The midwife performance questionnaire covered 10 closed questions with a Likert scale ranging from 1-5 where 5 is for strongly agree and 1 is for strongly disagree. Then, the response was categorized into 2 , Low (average score $<80 \%$ ) and High (average score $>80 \%$ ). The question concerning the knowledge consisted of 8 closed with the same Likert scale with 3 categories of responses, less (a total score of 1-14), Sufficient (a total score of 15-27), and Good (a total score of 28-40). The question concerning motivation consisted of 8 closed questions with the same Likert scale and the response was categorized into 2, Low (a total score of $<60 \%$ ) and High (a total score of $>60 \%$ ). The question concerning leadership consisted of 6 closed questions with the same Likert scale with 2 categories of responses, Low (a total score of $<60 \%$ ) and High (a total score of $>60 \%$ ). This research was approved by the Ethical Committee of Sekolah Tinggi Ilmu Kesehatan Muhammadiyah Gombong, Indonesia and it used guidelines from the Declaration of Helsinki. It was declared that there was no conflict of interest.

Statistical Analysis, this study used STATA (version.13; College Station, TX, USA: Stata Corp) to analyze the data. The data were analyzed using a quantitative approach including univariate analysis and bivariate analysis. The data were analyzed to identify factors affecting the performance of village midwives in the implementation of EMAS program in Kebumen District, Central Java Province, Indonesia. In particular, the univariate analysis was to examine a description of the frequency distribution between independent and dependent variables as well as the variation of each variable. Bivariate analysis was performed to show whether there is a relationship between the dependent variables and independent variables performed using statistical testing procedures/hypothesis. It applied a non-parametric test namely Chi-Square to test two independent samples with a significance p-value of 0.05 and Confidence Interval (CI) of $95 \%$. The test shows a significant relationship if the $p$-values are $<0.05$, otherwise, it shows a non-significant relationship if it is $>0.05$.

\section{Results and Discussion}

\subsection{Result}

In this study, the midwives' performance refers to the result of midwives' activities in performing services in the villages based on the cumulative results of K4 coverage. Based on these indicators, if $\mathrm{K} 4$ and childbirth services performed by midwives reach the target, then the performance will be categorized as 'good'. On the other hand, if the K4 and childbirth services do not reach the target, then it is categorized as 'Less'. Based on Table 1, the coverage of K4 
$<95 \%$ was 246 (29.9\%), lower than the coverage of $\mathrm{K} 4 \geq 95 \%$ with 576 (70.1\%). It means that $\mathrm{K} 4$ coverage in Kebumen District is mostly in accordance with the target of minimum service standard. The childbirth services assisted by midwives reached $480(58.4 \%)$ while childbirth without the assistance of midwives reached $41.6 \%$. It means that the coverage of childbirth services assisted by midwives can be categorized as 'Good' and appropriate with the target.

Table 1. Characteristic and Midwives performance

\begin{tabular}{|c|c|c|}
\hline Variable & Number & Percent \\
\hline \multicolumn{3}{|l|}{ K4 } \\
\hline$\geq 95 \%$ & 576 & 70.1 \\
\hline$<95 \%$ & 246 & 29.9 \\
\hline \multicolumn{3}{|l|}{ Giving Birth in Midwifery } \\
\hline$\geq 90 \%$ & 480 & 58.4 \\
\hline$<90 \%$ & 342 & 41.6 \\
\hline \multicolumn{3}{|l|}{ Performance } \\
\hline Low & 582 & 70.8 \\
\hline Good & 240 & 29.2 \\
\hline \multicolumn{3}{|l|}{ Age (years) } \\
\hline $22-31$ & 342 & 41.6 \\
\hline $32-41$ & 480 & 58.6 \\
\hline \multicolumn{3}{|l|}{ Tunure (years) } \\
\hline $1-9$ years & 396 & 48.2 \\
\hline $10-18$ years & 426 & 51.8 \\
\hline \multicolumn{3}{|l|}{ Knowledge } \\
\hline Less $(<5.6)$ & 216 & 26.3 \\
\hline Sufficient (5.6-7.5) & 444 & 54.0 \\
\hline Good $(7.6-10)$ & 162 & 19.7 \\
\hline \multicolumn{3}{|l|}{ Training } \\
\hline Less $(<5)$ & 774 & 94.2 \\
\hline Complete $(=5)$ & 48 & 5.8 \\
\hline \multicolumn{3}{|l|}{ Reward } \\
\hline No & 414 & 50.4 \\
\hline Yes & 408 & 49.6 \\
\hline \multicolumn{3}{|l|}{ Supervision } \\
\hline Low & 354 & 43.1 \\
\hline Good & 468 & 56.9 \\
\hline \multicolumn{3}{|l|}{ Facilities } \\
\hline None & 24 & 2.9 \\
\hline Less & 564 & 68.6 \\
\hline Complete & 234 & 28.5 \\
\hline \multicolumn{3}{|l|}{ Leadership } \\
\hline Low & 408 & 49.6 \\
\hline Good & 414 & 50.4 \\
\hline \multicolumn{3}{|l|}{ Attitude } \\
\hline Negative & 402 & 48.9 \\
\hline Positive & 420 & 51.1 \\
\hline \multicolumn{3}{|l|}{ Motivation } \\
\hline Low & 342 & 41.6 \\
\hline Good & 480 & 58.4 \\
\hline
\end{tabular}


The midwives' age ranges from 22-41 years. The Skewness test showed that the age distribution was normal (Skew: SE Skew = -0.246: $0.207=-1.188$ ). In the analysis, the respondents were grouped into two age groups, 22-31 years and 32-41 years.

The tenure was grouped into two, 1-9 years and 10-18 years. Midwives with a tenure of 118 years showed detailed values of the mean (10), median (12), mode (16), and SD (6.27). In addition, the Skewness test showed that the age of midwives was normally distributed (Skew: SE Skew $=-0.071: 0.207=-0.343)$. The study revealed a total of 426 midwives $(51.8 \%)$ with 10-18 years of tenure and 396 midwives (48.2 \%) with 1-9 years of tenure.

In detail, most of the midwives have 'sufficient' knowledge (444 midwives or $54.0 \%$ ). Then, 216 midwives (26.3\%) have 'less' knowledge while 162 midwives $(19.7 \%)$ have 'good' knowledge. The training for midwives was categorized into two: less $(<5$ times $)$ and complete (= 5 times). The majority of village midwives had poor training status (129 midwives or 94.2 $\%$ ). In this district, $50.4 \%$ of the midwives received rewards and the rest did not $(49.6 \%)$.

In this case, the supervision was to supervise the midwives and it was conducted by the District Health Office or Primary Health Care. The supervision was categorized into two, less ( $<2$ times a year) and good $(\geq 2$ times a year). The study showed that $56.9 \%$ of the midwives were in a 'good' category, while the rest $(43.1 \%)$ was in a 'less' category.

Most midwives in this district have low facilities (68.6\%), complete facilities $(28.5 \%)$, and no have facilities $(2.9 \%)$ to supports the implementation of EMAS program. Regarding leadership, $50.4 \%$ of midwives have good leadership, while $49.6 \%$ have low leadership. In terms of attitudes, 420 midwives $(51.1 \%)$ have positive attitudes and 402 midwives $(48.9 \%)$ show negative attitudes. Then, $58.4 \%$ of midwives have good motivation in providing health services including the implementation of EMAS program. This value is higher compared to midwives with lower motivation [Table 1].

The relationship analysis of midwives' age and performance in the village revealed that $73.7 \%$ of the midwives aged $22-31$ years and $68.8 \%$ of the midwives aged $32-41$ years have low performance. Otherwise, $26.3 \%$ of midwives aged 22-31 years and $31.2 \%$ of the midwives aged 32-41 years have high performance. Table 2 showed p-values of $>\alpha$ meaning that the midwives' age and performance have no significant relationship. Table 2 showed that OR values of midwives aged 22-31 years with chances 1.3 times higher to have low performance compared to those aged $32-41$ years.

In addition, the analysis of the midwives' tenure and performance showed that $72.7 \%$ of midwives with 1-9 years of tenure and $69 \%$ of the midwives with $10-18$ years of tenure have low performance. However, $27.3 \%$ of midwives with $1-9$ years of tenure and $31 \%$ of the midwives with 10-18 years of tenure have good performance. Table 2 showed $p$-values of $>\alpha$ meaning that the midwives' tenure and performance have no significant relationship. Moreover, Table 2 showed OR values of midwives with 1-9 years of tenure have chances 1.2 times higher to have low performance compared to those working for 10-18 years.

Based on the analysis relationship between training and midwives' performance, $72.9 \%$ of the midwives in the less training group have low performance and $7.5 \%$ of the midwives in the complete training group have good performance. Otherwise, $27.1 \%$ of the midwives in the less training group have good performance and $62.5 \%$ of the midwives in the complete training group have good performance. Table 2 showed that p-values $<\alpha$ meaning that there is a significant relationship between training and midwives' performance. OR values showed that midwives in the less training group have chances 4.5 times higher to have low performance compared to those in the complete training group.

Based on the analysis of the relationship between supervision and midwives' performance, $89.8 \%$ of the midwives in the low supervision and $56.4 \%$ of the midwives in the high 
supervision group have low performance. Otherwise, $10.2 \%$ of the midwives in the low supervision group and $43.6 \%$ of the midwives in the high supervision group have high performance. Table 2 showed $p$-values of $<\alpha$ meaning that supervision and performance have a significant relationship. OR values showed that midwives with low supervision have chances 6.8 times higher to have low performance compared to those with high supervision.

Based on the analysis of midwives' motivation and performance, $86 \%$ of the midwives in the low motivation category and $60 \%$ of the midwives in the high motivation have low performance. Otherwise, $14 \%$ of the midwives in the low motivation category and $40 \%$ of the midwives in high motivation category have high performance. Table 2 showed $p$-values of $<\alpha$ meaning that midwives' motivation and performance have a significant relationship. OR values showed that midwives with low motivation have chances 4 times higher to have low performance compared to those with high motivation show in Table 2.

Table 2. Bivariate analysis between each variable with midwifery performance

\begin{tabular}{|c|c|c|c|c|c|c|}
\hline \multirow{2}{*}{ Variable } & \multicolumn{6}{|c|}{ Midwifery Performance } \\
\hline & Amount & \%Low & Amount & \%Good & OR $(95 \% \mathrm{CI})$ & p-value \\
\hline \multicolumn{7}{|l|}{ Aged (years) } \\
\hline $22-31$ & 252 & 73.7 & 90 & 26.3 & 1 & \multirow{2}{*}{0.663} \\
\hline $32-41$ & 330 & 68.8 & 150 & 31.2 & $1.27(0.598-2.710)$ & \\
\hline \multicolumn{7}{|c|}{ Length of working (years) } \\
\hline $1-9$ & 288 & 72.7 & 108 & 27.3 & 1 & \multirow{2}{*}{0.772} \\
\hline $10-18$ & 294 & 69.0 & 132 & 31.0 & $1.20(0.572-2.507)$ & \\
\hline \multicolumn{7}{|l|}{ Training } \\
\hline Less $(<5)$ & 564 & 72.9 & 210 & 27.1 & 1 & \multirow{2}{*}{0.047} \\
\hline Complete $(=5)$ & 18 & 37.5 & 30 & 62.5 & $4.48(1.016-19.723)$ & \\
\hline \multicolumn{7}{|l|}{ Supervision } \\
\hline Low & 318 & 89.8 & 36 & 10.2 & 1 & \multirow{2}{*}{$<0.001$} \\
\hline Good & 264 & 56.4 & 204 & 43.6 & $6.83(2.625-17.747)$ & \\
\hline \multicolumn{7}{|l|}{ Reward } \\
\hline No & 304 & 73.5 & 110 & 26.5 & 1 & \multirow{2}{*}{0.047} \\
\hline Yes & 278 & 68.1 & 130 & 31.9 & $1.30(0.621-2.723)$ & \\
\hline \multicolumn{7}{|l|}{ Motivation } \\
\hline Low & 294 & 86.0 & 48 & 14.0 & 1 & \multirow{2}{*}{0.002} \\
\hline Good & 288 & 60.0 & 192 & 40.0 & $4.08(1.709-9.756)$ & \\
\hline
\end{tabular}

\subsection{Discussion}

Based on the result of training, supervision, and motivation related to midwives' performance, the government has to consider policies and follow-up actions to improve the performance of midwives in villages in the implementation of EMAS program.

The midwives' age and performance have no significant relationship in the implementation EMAS program. It is in line with D'Ambruoso et al [16] in which midwives' age and performance do not show a significant relationship in maternal and neonatal services. On the other hand, it contradicts with Rambu Ngana, Myers, \& Belton [17] in which they found that midwives' age and performance have a significant relationship. Midwives, as health workers and pioneers of health programs to reduce maternal mortality rate that is used as an indicator of health status, have to possess mental and physical maturity in various actions including in decision making [17]. Therefore, they have to be mature in thinking and taking action. Gibson Makowiecka, Achadi, Izati, \& Ronsmans [18] state that age is an individual variable that the 
older the persons, the more mature they will be. Even, more information will affect their performance. However, age is not always a benchmark that showed the higher the maturity, the better the performance because some other factors may affect the performance of midwives. It has to be followed by sufficient knowledge and training for village midwives [19].

In addition, tenure and midwives' performance have no significant relationship in the implementation of EMAS program. OR 1.2 values indicate that midwives with 1-9 years of tenure have higher chances (1.2 times) to have a low performance compared to those with 1018 years of tenure.

This result is in line with a study conducted by Ronsmans et al [20] in which tenure and midwives' performance in maternal and neonatal health services have no significant relationship. However, Achadi et al [21] found that tenure and midwives' performance have a significant relationship. Working experiences indirectly determines the performance and behavior of individuals. The tenure and experiences in managing cases will affect the individuals' skills [22].

Training and midwives' performance have a significant relationship in the implementation of EMAS program. OR showed that midwives with incomplete training have a chance 4.5 times higher to have a low performance compared to those receiving complete training. It is in accordance with the study conducted by Ronsmans et al [23] in which training and midwives' performance showed a significant relationship. Training is one of the ways to develop human resources and it is a part of a formal education process that aims to improve individuals' performances and skills.

Reward and midwives' performance have no significant relationship in the implementation of EMAS program. OR showed that midwives who do not receive rewards had chances 1.3 times higher to have a low performance compared to those who receive the rewards. Furthermore, Achadi et al [21] found that there is no significant relationship between additional income and the performance of midwives. On the other hand, found that additional income and village midwives have a significant relationship [24]. Huang et al argue that income or reward can motivate workers' performance and good rewards will motivate them to have higher achievement [25].

The study showed that supervision and midwives' performance have a significant relationship in the implementation EMAS program. Furthermore, Achadi et al also found a similar finding [21]. Otherwise, Ronsmans et al found that supervision and midwives' performance have no significant relationship [23]. If the midwives were not supervised and their performance was low or the supervision coverages were not comprehensive, then they required guidance from their seniors to carry out their duties including in the implementation of EMAS program. Furthermore, they have to possess sufficient knowledge of standard midwifery services [2].

Table 2 showed that motivation and midwives' performance have a significant relationship. In addition, Ronsmans et al [15] shared similar findings. On the other hand, Achadi et al [16] found that midwives' motivation and performance have no significant relationship.

Salenius [17] states that motivation is an internal condition or mental health that drives individual performance behaviors in achieving satisfaction and reducing imbalances. The results of this study indicate that midwives' motivation has a significant relationship in the implementation of EMAS program. Some factors contributing to low motivation cover economic dissatisfaction/amount of income, inconvenient working environment, and a gap between midwives working in the urban and rural areas [24]. 


\section{Conclusion}

It is crucial for the government to increase the midwives' motivation. It can be done through providing rewards both material and non-material such as easy access to training and higher education. The village midwives carry out a cross-sectoral collaboration with relevant agencies in the village and sub-district, community leaders, and religious leaders to disseminate information on EMAS program and its benefits for the community.

The limitation in this study was used an online questionnaire and it was shared via Facebook. Therefore, the participants of the study need a computer, internet access, and a Facebook account. The questionnaire used Bahasa Indonesia without completed with a local language. Thus, the participants have to be able to read and comprehend the language.

This study has no control group, so the measurement cannot be compared. This study discusses the factors affecting the performance of village midwives in the implementation of EMAS program. However, this study covered a limited number of variables regarding the midwives' performance. It only involved 10 factors (age, tenure, knowledge, training, reward, supervision, facilities, leadership, attitude, and motivation). Therefore, there is a possibility that other factors might influence the result of the study. Furthermore, it used limited measurement parameters for each variable, both the independent and dependent variables. Hence, other representative parameters can describe the values of each variable that is not covered in this study.

\section{Acknowledgment}

We acknowledge that all midwives' contribution and cooperation made the study possible. This research was financially supported by Sekolah Tinggi Ilmu Kesehatan Muhammadiyah Gombong, Central Java, Indonesia

\section{References}

[1] WHO, "Maternal Mortality Fact sheet," Matern. Heal., 2015.

[2] RISKESDAS, "Riset Kesehatan Dasar 2018," Kementrian Kesehat. Republik Indones., 2018.

[3] N. Tickle, M. Sidebotham, J. Fenwick, and J. Gamble, "Women's experiences of having a Bachelor of Midwifery student provide continuity of care," Women and Birth, 2016, doi: 10.1016/j.wombi.2015.11.002.

[4] Riskesdas 2018, "Hasil Utama Riset Kesehatan Dasar," Kementrian Kesehat. Republik Indones., 2018, doi: 1 Desember 2013.

[5] C. B. Forrest, L. Shi, S. Von Schrader, and J. Ng, "Managed care, primary care, and the patientpractitioner relationship," J. Gen. Intern. Med., 2002, doi: 10.1046/j.1525-1497.2002.10309.x.

[6] 6(1). http://doi.org/10.1186/s13613-015-0104-6 Deye, N., Vincent, F., Michel, P., Ehrmann, S., Da Silva, D., Piagnerelli, M., ... Laterre, P.-F. (2016). Changes in cardiac arrest patientsâ€TM temperature management after the 2013 â€œTTMâ€ trial: Results from an international survey. Annals of Intensive et al., "Knowledge, attitudes and practices of mothers about feeding preschoolers," Fundam. Clin. Pharmacol., 2014, doi: 10.1111/fcp.12064.

[7] C. I. Baas, J. J. H. M. Erwich, T. A. Wiegers, T. P. de Cock, and E. K. Hutton, "Women's Suggestions for Improving Midwifery Care in The Netherlands," Birth, 2015, doi: 10.1111/birt.12185. 
[8] E. I. Feijen-De Jong, D. E. Jansen, F. Baarveld, C. P. Van Der Schans, F. G. Schellevis, and S. A. Reijneveld, "Determinants of late and/or inadequate use of prenatal healthcare in high-income countries: A systematic review," European Journal of Public Health. 2012, doi: 10.1093/eurpub/ckr164.

[9] K. K. Direktur, J. Bina, K. Masyarakat, K. Kesehatan, and R. N. Katalog, "PEDOMAN PELAYANAN ANTENATAL TERPADU," PEDOMAN PELAYANAN ANTENATAL TERPADU, 2010.

[10] S. Hutahean, perawatan antenatal. 2013.

[11] Riskesdas, "Hasil Utama Riset Kesehatan Dasar," Kementrian Kesehat. Republik Indones., 2018.

[12] D. M. Bond et al., "Planned early birth versus expectant management for women with preterm prelabour rupture of membranes prior to 37 weeks' gestation for improving pregnancy outcome," Cochrane Database of Systematic Reviews. 2017, doi: 10.1002/14651858.CD004735.pub4.

[13] S. R. Till, D. Everetts, and D. M. Haas, "Incentives for increasing prenatal care use by women in order to improve maternal and neonatal outcomes," Cochrane Database of Systematic Reviews. 2015, doi: 10.1002/14651858.CD009916.pub2.

[14] Dinas Kesehatan Kabupaten Kebumen, Profil Kesehatan Kabupaten Kebumen Tahun 2018. 2018.

[15] KEMENKES RI, Profil Kesehatan Indonesia Tahun 2019. 2019.

[16] W. J. Wang, M. Do, J. Hembling, and P. Ametepi, "Assessing the quality of care in family planning, antenatal, and sick child services at health facilities in Kenya, Namibia, and Senegal," DHS Anal. Stud., 2014.

[17] F. Rambu Ngana, B. A. Myers, and S. Belton, "Health reporting system in two subdistricts in Eastern Indonesia: Highlighting the role of village midwives," Midwifery, 2012, doi: 10.1016/j.midw.2011.09.005.

[18] 6(1). http://doi.org/10.1186/s13613-015-0104-6 Deye, N., Vincent, F., Michel, P., Ehrmann, S., Da Silva, D., Piagnerelli, M., ... Laterre, P.-F. (2016). Changes in cardiac arrest patientsâ€TM temperature management after the 2013 â€œTTMâ€ trial: Results from an international survey. Annals of Intensive et al., "Assessment of infant and young children feeding practices in zanzibar using the process for the promotion of child feeding (ProPAN) tool," Ann. Nutr. Metab., 2013, doi: $10.1159 / 000354245$.

[19] Ministry of Heath Indonesia, "Petunjuk teknis penggunaan Buku Kesehatan Ibu dan Anak," Minist. Heal. Indoneisa, 2015.

[20] C. Ronsmans et al., "Evaluation of a comprehensive home-based midwifery programme in South Kalimantan, Indonesia," Trop. Med. Int. Heal., 2001, doi: 10.1046/j.1365-3156.2001.00780. x.

[21] E. Achadi et al., "Midwifery provision and uptake of maternity care in Indonesia," Trop. Med. Int. Heal., 2007, doi: 10.1111/j.1365-3156.2007.01957. x.

[22] L. D’Ambruoso, E. Achadi, A. Adisasmita, Y. Izati, K. Makowiecka, and J. Hussein, "Assessing quality of care provided by Indonesian village midwives with a confidential enquiry," Midwifery, 2009, doi: 10.1016/j.midw.2007.08.008.

[23] K. Makowiecka, E. Achadi, Y. Izati, and C. Ronsmans, "Midwifery provision in two districts in Indonesia: How well are rural areas served?" Health Policy Plan., 2008, doi: 10.1093/heapol/czm036.

[24] P. Salenius, "Sociological and psychological effects of stillbirth: Theory, research, and midwifery," Br. J. Midwifery, 2019, doi: 10.12968/bjom.2019.27.10.616. 